Gathorne Robert Girdlestone. By J. Trueta. 22.8 $14 \mathrm{~cm}$. Pp. x $\cdots 101$, with 8 figures. 1971. Published for the Girdlestone Orthopaedic Society, Oxford, by the Oxford University Press. Price $£ 1 \cdot 50$.

Many readers will be familiar with the history of the early years of British orthopaedic surgery. This book makes an important contribution by describing the work of one man who devoted his life to the development of the Wingfield-Morris Orthopaedic Hospital in Oxford and the organisation of an area service to care for the crippled. Professor Trueta writes with affection about his former friend and in spite of his personal involvement he modestly regards his role "as that of a compiler rather than a contributor". The book is based on a collection of documents, many of them letters exchanged between Robert Jones and Girdlestone (G. R. G. as he is referred to throughout).

G. R. G. began his surgical career in general practice in Oswestry. He met Robert Jones at Baschurch and this led to a close and continuing friendship throughout the years. A serious chest injury in a motor-cycle accident to some extent determined G. R. G.'s future and his attitude to life. He was unable to serve overseas in the First World War but moved to Oxford to work in a military hospital in the Examination Schools and then to take charge of a hutted orthopaedic hospital in the grounds of the Wingfield Convalescent Home.

At the end of the war G. R. G., who was clearly aware of deficiencies that existed, began to create an orthopaedic service in the Oxford area. In 1919 Sir Robert Jones and he published The Care of Crippled Childrein. Proposed National Scheme. This document was the foundation of a plan which established orthopaedic hospitals with associated clinics throughout the country. At about the same time G. R. G. helped in setting up The Council for the Care of Cripples.

A close association developed between William Morris and Girdlestone: the former's generosity led to progressive improvements in the old Wingfield Hospital which was renamed the WingfieldMorris Orthopaedic Hospital. Lord Nuffield (as William Morris became) was undoubtedly influenced by G. R. G. and he contributed on many occasions to orthopaedic projects in this country and overseas. A final benefaction made possible the building of a new block and the creation of the Nuffield Orthopaedic Centre. This took place when the author was Professor of Orthopaedic Surgery and he played a vital part in fulfilling the plans which he had inherited from G. R. G.

Girdlestone died in 1950 and he was mourned by many. His teaching had been an inspiration to the men trained by him and the "Wingfield Spirit" had spread to many parts of the world. This book, published for the Girdlestone Society, does justice to his memory and is a fitting tribute to one of the founders of British orthopaedic surgery.-William WAUGH.

\title{
BOOKS OF ORTHOPAEDIC INTEREST
}

Orthopädische Therapie. (Orthopaedic Therapy.) By George Chapchal and Detlev Waignand. With the assistance of Harald ECKHARDT together with fourteen contributors. $26 \cdot 17 \cdot 5 \mathrm{~cm}$. Pp. xvi +533 , with 449 illustrations in 299 figures and 20 tables. Index. 1971. Stuttgart: Georg Thieme Verlag. Price DM 98.

As it is virtually impossible to discuss variations in treatment without an assessed description of the variations in the form and manifestation of the disease to be treated, a volume dealing only with treatment is usually found to be lacking. One exception to this is Camphell's Operative Orthopaedics in which enough clinical detail is given to make the choice of treatment a practical possibility. There is not enough clinical detail in this volume, and, while many useful variations of treatment are described and illustrated, their application to the individual cases is only lightly sketched in.

Gicht. (Gout.) Grundlagen, Klinik und Therapie. (Biochemistry, Clinical and Therapeutic.) By Dieter Paul MerTz. $19 \times 12 \mathrm{~cm}$. Pp. viii +264 , with 50 figures and 8 tables. Index. 1971. Stuttgart: Georg Thieme Verlag. Price DM 11.80.

This little flexible-backed pocket book contains almost all there is to know about gout histologically, metabolically and clinically. It falls a little short perhaps in the quality of the radiological illustrations, but these are a relatively unimportant part of the subject which is amply compensated for by the admirable list of references at the end of every chapter.

Reports on Rheumatic Diseases. Collected Reports (revised and with index) 1959-1971. Edited by Clifford Hawkins and H. L. F. Currey. $24 \times 18 \mathrm{~cm}$. Pp. 151, with 9 figures and 6 tables. Index. 1971. London: The Arthritis and Rheumatism Council for Research in Great Britain and the Commonwealth. Price 50p (medical students 25p). 